ISSN 2236-0859

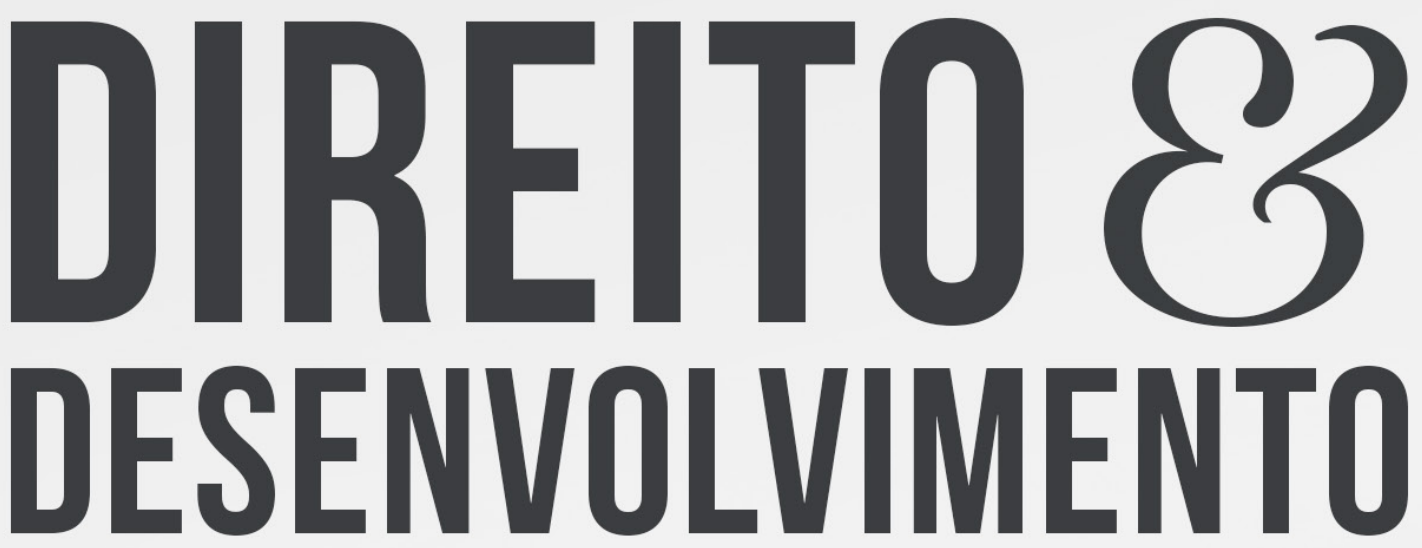

REVISTA DO PROGRAMA DE PÓS-GRADUAÇÃO EM DIREITO MESTRADO EM DIREITO E DESENVOLVIMENTO SUSTENTÁVEL

REPRESENTACÕOSES DA CRISE AMBIENTAL NA MÚSICA POPULARBRASILEIRA: SUSTENTABILIDADE COMO DIREITOHUMANO

RUI CARLOS DIPP JUNNOR

SÉRGIO RICARDO FERNANDES DE AQUINO 


\title{
REPRESENTAÇÕES DA CRISE AMBIENTAL NA MÚSICA POPULAR BRASILEIRA: SUSTENTABILIDADE COMO DIREITO HUMANO
}

\section{REPRESENTATIONS OF THE ENVIRONMENTAL CRISIS IN BRAZILIAN POPULAR MUSIC: SUSTAINABILITY AS HUMAN RIGHTS}

Recebido: $12 / 03 / 2019$

Aprovado: 17/06/2019
Rui Carlos Dipp Júnior ${ }^{1}$

Sérgio Ricardo Fernandes de Aquino ${ }^{2}$

\begin{abstract}
RESUMO:
O presente trabalho tem como tema a crise ambiental e delimitou-se a pesquisar representações dessa conjuntura na música popular brasileira para se averiguar como a Sustentabilidade pode ser entendida como Direito Humano. Trata-se de uma pesquisa bibliográfica cuja abordagem utilizada é o método hipotético-dedutivo. O objetivo geral é demonstrar como a crise ambiental, representada pela música popular brasileira, deve suscitar a importância da Sustentabilidade como genuíno Direito Humano. Conclui-se que, por meio da interdisciplinaridade, essa forma de manifestação artística pode favorecer o debate sobre a crise ambiental, porque as canções permitem a reflexão sobre o assunto no momento em que revelam ideias, pensamentos e sentimentos capazes de inspirar uma maior consciência nos seres humanos em relação à compreensão e importância da sustentabilidade em âmbito local e planetário.
\end{abstract}

Palavras-chave: Crise Ambiental. Música Popular Brasileira. Sustentabilidade.

\begin{abstract}
:
The present work has as its theme the environmental crisis and delimited itself to research representations of this conjuncture in Brazilian popular music to find out how Sustainability can be understood as Human Right. This is a bibliographical research whose approach used is the hypothetical-deductive method. The general objective is to demonstrate how the environmental crisis, represented by Brazilian popular music, should raise the importance of Sustainability as a genuine Human Right. It is concluded that, through interdisciplinarity, this form of artistic expression can favor the debate about the environmental crisis, because the songs allow the reflection on the subject at the moment they reveal ideas, thoughts and feelings capable of inspiring a greater awareness in the human beings in relation to the understanding and importance of sustainability at a local and global level.
\end{abstract}

Keywords: Environmental Crisis. Popular Brazilian Music. Sustainability.

1 Mestrando em Direito pela Faculdade Meridional - IMED. Bacharel em Ciências Jurídicas e Sociais pela Universidade de Passo Fundo (2015). Advogado. Membro do Grupo de Pesquisa e Extensão Cinema, Direitos Humanos e Sociedade: vias para o empoderamento (IMED/CNPq). Atualmente é professor universitário na Universidade de Passo Fundo no Curso de Música (bacharelados e licenciatura) e no Curso de Especialização em Música.

2 Doutor em Ciência Jurídica pela Universidade do Vale do Itajaí - UNIVALI (2013). Mestre em Ciência Jurídica pela Universidade do Vale do Itajaí (2007). Especialização em Administração pela Universidade Independente de Lisboa em convênio com a Universidade do Estado de Santa Catarina - UDESC (2005) e Graduado em Direito pela Universidade do Vale do Itajaí (2003). Professor Permanente do Programa de Pós-Graduação em Direito (PPGD) - Mestrado - da Faculdade Meridional - IMED. E-mail: sergiorfaquino@gmail. com 


\section{INTRODUÇÃO}

Este artigo tem como tema a crise ambiental e delimita-se a abordar suas representações na música popular brasileira como forma de entender a Sustentabilidade como Direito Humano. Para tanto, a pesquisa encontra-se vinculada a conteúdos relacionados às Teorias da Sustentabilidade, principalmente no que se refere à dimensão ambiental.

A abordagem utilizada neste trabalho na sua fase de investigação fundamenta-se no método hipotético-dedutivo. Utiliza-se como técnica de pesquisa a bibliográfica e documental, bem como categorias ${ }^{3}$ e conceitos operacionais ${ }^{4}$.

O problema de investigação é sintetizado no seguinte questionamento: a música popular brasileira, relacionada com a temática da Sustentabilidade entendida como Direito Humano, pode ampliar e esclarecer a necessidade de maior debate sobre a crise ambiental?

Por conta desse cenário, argumenta-se uma hipótese positiva à referida pergunta, isto é, de que a música popular brasileira, conjugada à matéria da Sustentabilidade, amplifica, potencializa e elucida a imprescindibilidade de maiores discussões sobre a crise ambiental.

Como hipótese no seu sentido negativo, propõe-se que os efeitos da crise ambiental não podem ser retratados, tampouco debatidas com seriedade acadêmica a partir daquilo que a música retrata, pois faltariam elementos de maior rigor metodológico que poderiam aferir os efeitos da crise ambiental e sua necessidade de entendimento a partir da Sustentabilidade como Direito Humano.

Dessa maneira, propõe-se como objetivo geral demonstrar como a crise ambiental, representada pela música popular brasileira, deve suscitar a importância da Sustentabilidade como genuíno Direito Humano. De forma mais pormenorizada, descreve-se como objetivos específicos: a) explanar sobre a importância da música popular na temática da sustentabilidade em sua dimensão ambiental; e, b) identificar representações da crise ambiental na música popular brasileira como forma de suscitar a necessidade da Sustentabilidade como Direito Humano.

Para atingir os objetivos acima delineados, e visando tecer reflexões e reunir abordagens sobre o assunto, o texto está estruturado em duas partes. Preliminarmente, assenta-se apontamentos sobre a relevância da música popular como suporte e apoio aos discursos da sustentabilidade. No segundo momento, discorre-se sobre as representações da crise ambiental na música popular brasileira.

Ressalta-se que é uma pesquisa de cunho interdisciplinar, focado inclusive na conexão entre Direito e Música. Nesse sentido, não se restringe a examinar tão somente as letras das composições, contempla-se igualmente averiguar suas interconexões com o plano musical sonoro concebido pelos compositores. Por isso, recomenda-se a leitura do presente texto juntamente com a audição das músicas ou dos trechos de músicas que são citados ao longo do artigo.

Consigna-se que as respostas científicas aos mais variados problemas do mundo nem sempre se encontram reunidas em uma única seara do conhecimento e, em relação à crise ambiental, não poderia ser diferente. Destarte, justifica-se a pertinência do presente objeto de estudo para a comunidade acadêmica, porque é um tema de âmbito local e global que, além de ser atual, revela-se identicamente fundamental para as futuras gerações.

3 “[...] palavra ou expressão estratégica à elaboração e/ou à expressão de uma ideia”. (PASOLD, 2015, p. 205).

4 "[...] definição estabelecida ou proposta para uma palavra ou expressão, com o propósito de que tal definição seja aceita para os efeitos da ideia exposta”. (PASOLD, 2015, p. 205).

5 Os autores utilizarão o seguinte Conceito Operacional para a Categoria mencionada: É a compreensão ecosófica acerca da capacidade de resiliência entre os seres e o ambiente para se determinar - de modo sincrônico e/ou diacrônico - quais são as atitudes que favorecem a sobrevivência, a prosperidade, a adaptação e a manutenção da vida equilibrada. 


\section{DA IMPORTÂNCIA DA MÚSICA POPULAR NA TEMÁTICA DA SUSTENTABILIDADE EM SUA DIMENSÃO AMBIENTAL}

Pensa-se que a música é uma forma de linguagem que possibilita a comunicação e a disseminação de diferentes ideias e de pensamentos à sociedade. Paralelamente, consoante leciona Aquino, a Sustentabilidade pode ser identificada como "[...] um novo valor centrado na Responsabilidade e permite a compreensão da transição de outro paradigma de manutenção da vida na Terra que não esteja fundamentado, exclusivamente, no crescimento econômico" (2014, p. 46).

Por conta dessa compreensão, na seara da Sustentabilidade, acredita-se que não somente é possível relacionar Direito e Arte, como, também, é viável relacionar a arte dos sons por meio de representações musicais da crise ambiental na música popular brasileira, mormente no que concerne às letras das mais variadas canções que abordam o tema.

Naturalmente, os diferentes debates sobre a questão da Sustentabilidade, em sua dimensão ambiental, bem como da crise ambiental, podem ser encontrados em vários livros que investigam essa matéria. Por outro lado, essa situação não significa que um estudante ou profissional interessado sobre essas questões deva ficar preso somente à leitura de livros técnicos científicos, isto é, um pesquisador pode ir além dos livros de modo a encontrar maiores subsídios e reflexões a seus argumentos. A arte é um caminho para se viabilizar (e sensibilizar sobre) essa finalidade. Segundo Oliveira (2017, p. 51):

\footnotetext{
A linguagem é reveladora das diversas formas de arte. Na música os sons trazem mensagem pela harmonia. A medida de seu uso é dada pela situação social. A entonação altera seu significado. Em verdade, qualquer emanação de voz produz uma alteração no outro. Consubstancia uma mensagem que pode ser entendida e captada de diversas maneiras.
}

De fato, quando o referido autor destaca que a música é capaz de transmitir mensagens, ou seja, quando um compositor opta em sua composição em utilizar uma progressão harmônica em determinada tonalidade, esse o faz para aproximar o uso dos acordes de funções que levam ao ouvinte, exemplificativamente, a sensações de tensão ou de repousa. Pode-se inferir inclusive que, noutros momentos, uma mesma melodia vocal executa em regiões diferentes da escala musical podem denotar sentimentos diversos sobre uma determinada letra de canção, como tristeza, raiva, revolta, conformação, alegria, dentre outros.

Nessa linha de pensamento, e ao dissertar sobre música contemporânea, Copland (2013, p. 167) sinaliza que "Os compositores variam imensamente em alcance e objetivo, em temperamento e expressão. Por isso, a música contemporânea transmite não um tipo, mas muitos tipos diferentes de experiência musical".

Nesse rumo, as artes podem ser um suporte de sustentação a esses debates e, além dessas questões, pode-se levar sua mensagem a públicos cada vez maiores. Dessa forma, a música, de forma geral, e mais especificamente a música popular, pode ser um veículo promotor às diferentes discussões sobre sustentabilidade e crise ambiental.

Ao explicar sobre música popular urbana, por exemplo, Tavares e Cit (2013, p. 90) afirmam que essa "Consiste na música feita por um compositor conhecido e que normalmente alcança todas as camadas da sociedade. É característico dos centros urbanos e recebe apoio da mídia".

Presume-se, nesse caso, que se a música popular pode atingir todas as classes sociais, faz sentido se aproveitar de canções populares para educar as pessoas, levá-las a outros níveis 
de dimensões reflexivas sobre os problemas que o planeta Terra vem enfrentando ao longo dos tempos: poluição, descaso, degradação ambiental, lixo, água.

Por esse motivo, malgrado a indústria cultural permita críticas negativas quando esta utiliza-se da música em prol de interesses estritamente econômicos, sem preocupação principal com a sua qualidade em termos de materiais e técnicas de composição artística, paradoxalmente é viável crer que há possibilidades dos mais variados profissionais fazerem uso dos produtos musicais gerados pela mesma a fim de reunir diferentes pontos de vista sobre a crise ambiental. Nesse sentido, a música desejada pela indústria cultural é caracterizada basicamente da seguinte forma:

Refere-se à música feita para ser assimilada por um grande número de pessoas. Sua estrutura de composição é bastante simples e sua intenção é incentivar o consumo alienado da população. Esse tipo de música permanece na moda por um curto período de tempo e é divulgado por todos os meios de comunicação, sendo logo descartado e trocado por outro sucesso do momento. (TAVARES; CIT, 2013, p. 91).

Se a música almejada pela indústria cultural tem como alvo atingir o maior número possível de ouvintes, de consumidores, num primeiro momento, esse cenário parece ser positivo, já que muitas músicas que originalmente possam ter tido esse propósito. Atualmente, essas podem instigar e inspirar nas pessoas uma consciência sobre como a sociedade pode pensar, mudar e agir diante de problemas sociais ligados à crise ambiental.

A partir desse entendimento, defende-se que músicas populares podem conter bons materiais de estudo em ambientes acadêmicos. Não obstante a indústria cultura produza material musical conforme a moda de cada época, muitas músicas acabando não caindo nessa armadilha e ressurgem de tempos em tempos e se tornam verdadeiros clássicos. Por esse motivo, acredita-se ser sempre temerário ter qualquer espécie de preconceito sobre determinadas músicas que se apresentam nesse contexto em comento, de serem meros produtos de consumo de fácil compreensão.

Ademais, essas autoras advertem que os mais variados gêneros musicais "[...] fazem parte da realidade musical humana e, por isso, devem ser abordados na escola, estudados, aprofundados e criticados, independentemente dos gostos individuais da turma ou até do professor" (TAVARES; CIT, 2013, p. 91).

Presume-se que a música é uma ferramenta com capacidade para revelar o contexto ambiental do planeta ou de uma determinada localidade, e com isso, contribuir para a resolução de problemas voltados à crise ambiental. Nessa perspectiva, ao se analisar as artes do ponto de vista mercadológico, Zagonel afirma que "É possível olhar a comercialização da arte não só pelas distorções que isso gera, mas também pelos benefícios trazidos, como [...] a difusão das diferentes expressões artísticas para um número cada vez maior de pessoas" (2012, p. 31).

Nesse contexto pode-se inferir que músicas populares que retratem temas ligados à natureza, ao meio-ambiente e ao ambiente podem ter como origem o interesse da indústria cultural quando da divulgação do trabalho musical de determinados artistas. Logo, a indústria cultural apresenta-se de forma positiva em relação a esses aspectos, e, por conseguinte, mensagens com um viés educacional podem chegar ao consumidor.

Consoante Zagonel (2012, p. 28), "A arte e a cultura são um meio de expressão humana, um meio de comunicação importante". Acredita-se, nesse caso, que a música, como uma das formas de arte, não tem a função restrita do lúdico, do mero prazer, do ouvir por ouvir, ou seja, essa exerce um papel fundamental na construção de uma sociedade. Nesse sentido, a autora acrescenta que "A arte não se faz de forma isolada, ela está diretamente ligada ao contexto em que é produzida" (ZAGONEL, 2012, p. 34). 
É crível que a música não se presta simplesmente ao adorno, a uma determinada paisagem sonora específica. Compreender essa arte é uma possibilidade de buscar maior harmonia com o seu próprio eu em relação ao planeta. Por esse motivo, urge trazer para o debate em comento músicas populares que explorem a matéria sobre crise ambiental, o que é essencial para a completude da formação humana. Por conseguinte, todo e qualquer educador pode aproveitar-se disso, especialmente na área jurídica, pois sozinha, está nem sempre traz explicações e soluções sobre a conjuntura e problemas da vida.

Ao se observar esses argumentos com mais atenção, percebe-se que a música popular brasileira se manifesta principalmente por meio de canções e faz parte dessa linguagem musical de forma bastante ampla. Nesse caso, quando se adota de forma conveniente uma postura radicalmente aberta, pode-se chegar a um conceito que envolve uma diversidade muito grande de estilos, de concepções e de composições musicais, como se pode inferir da explicação acerca do conceito em comento por Costa (2011, p. 109): "Radicalmente abertas: consideram música popular brasileira toda e qualquer canção produzida no Brasil independentemente de qualidade, origem de seu ritmo ou língua que utiliza”.

Nessa lógica, basta que a canção seja criada no Brasil para ser classificada como música popular brasileira, malgrado existam obras musicais brasileiras que levam o rótulo de MPB - Música Popular Brasileira - em detrimento de várias músicas que em teoria não se enquadrariam neste campo, por exemplo, por não se encaixar em padrões de qualidade musical que se verificam em certos gêneros: como a bossa nova (COSTA, 2011, p. 109/110). Compreendese que, em realidade, a MPB - considerada como gênero musical - faz parte de um sistema maior, isto é, está dentro do que se entende por Música Popular Brasileira, conforme leciona ainda o referido autor

É diante dessa diversidade de posições estéticas (samba tradicional, Bossa Nova, canção de protesto etc.) que surge a denominação 'Música Popular Brasileira' e a sigla 'MPB'. [...] para nós, a expressão e a sigla não designam a mesma coisa, sendo a segunda um subconjunto da primeira. (COSTA, 2011, p. 111).

Desse modo, importa ressaltar que é presumível que a música popular brasileira não se restringe ao que se denomina de MPB. Essa condição é perceptível também em Jairo Severiano (In: Uma história da música popular brasileira, 2017), que de forma didática esquematiza todo um panorama temporal dividindo-o em quatro partes a saber: a) a formação (1770-1928); b) a consolidação (1929-1945); c) a transição (1946-1957); e, d) a modernização (1958-).

É admissível supor, a partir desses argumentos, que este autor assume uma posição radicalmente aberta sobre o que se considera como música popular brasileira. Nesse caso, a situação parece ser uma posição mais salutar ao processo de exposição e de argumentações sobre esse tema, pois por meio desse entendimento se aceita incluir todos os gêneros e estilos musicais desse campo que foram produzidos no Brasil sem que se corra o risco de excluir "esta" ou "aquela" obra musical que se queira analisar.

\section{REPRESENTAÇÕESDACRISE AMBIENTALNAMÚSICA POPULAR BRASILEIRA E A SUSTENTABILIDADE ENTENDIDA COMO DIREITO HUMANO}

O debate sobre a crise ambiental e suas representações na música popular pode ter como ponto de partida o trabalho de Fernando Estenssoro (2014). Trata-se de uma obra sobre o debate a nível político e global acerca da crise ambiental e as relações de poder. Para tanto, 
resgata um panorama histórico sobre a temática ambiental, entre os anos 1945 e 1992, e como se procedeu essa pauta na agenda política mundial.

O referido livro revela como marco histórico a Conferência da Organização das Nações Unidas (ONU) sobre o Meio Ambiente Humano, em Estocolmo, capital da Suécia, no ano de 1972. Nesta conferência houve preocupação com a degradação do meio ambiente, tempos em que se vive a chamada civilização industrial (SAAVEDRA, 2014, p. 15).

Especificamente em relação à Parte I, A crise ambiental: reflexo das mudanças no imaginário geográfico político hegemônico, no capítulo 1, há um questionamento sobre o que é a crise ambiental - desajustes populacionais, desequilíbrios entre Norte/Sul, consumismo, desenvolvimento tecnológico com impactos desconhecidos, fortes migrações - campo/cidade, urbanização crescente, perda da biodiversidade, contaminação do planeta, desmatamento acelerado, falta de acesso a recursos mínimos por grande parte da população mundial água, moradia entre outros -, feminização da pobreza - mulheres com os piores trabalhos (SAAVEDRA, 2014). Nesse sentido, o referido autor (2014, p. 25, grifos do autor) afirma que:

Com a ideia de crise ambiental quer-se expressar o fenômeno paradoxal que foi o crescimento econômico em si, pelo elevado nível de desenvolvimento e padrão de vida alcançado pela civilização industrial, em que o Primeiro Mundo é o exemplo emblemático, que gerou problemas de caráter ecológico e ambiental de tão grande magnitude que, pela primeira vez na História colocou-se em risco a continuidade da vida humana na Terra, bem como o processo de vida do próprio planeta.

Os compositores Ed Motta e Rafael Cardoso, na obra "Vamos Dançar", de 1988, apresentam uma letra de música que consegue refletir alguns pontos referentes à citação acima exposta por Saavedra. Veja-se:

Eu não nasci pra trabalho / Eu não nasci pra sofrer / Eu percebi que a vida / É muito mais que vencer / Já dirigi automóveis / Já consumi capital / Já decidi que o dinheiro / Não vai pagar, não vai pagar a minha paz / Vamos dançar lá na rua / Vamos dançar pra valer / Vamos dançar enquanto é tempo / Nos aplicar a viver ${ }^{6}$.

Nessa letra, no que se refere ao crescimento econômico e ao padrão de vida, percebe-se que a canção denota uma situação no qual um personagem retrata um pensamento de que, por mais que se trabalhe com o intuito de ter poder aquisitivo, essa condição não é suficiente para que a existência humana faça sentido. Por esse motivo, a Sustentabilidade não pode ser uma expressão de vida voltada às ideologias no seu sentido fraco, ou seja, de impossibilitar as diferentes mudanças no viver e conviver, mas, como Direito Humano ${ }^{7}$, deve trazer a pluralidade de horizontes para que ocorra a transformação dos cenários de sobrevivência, de miséria, de riquezas materiais ostensivas e intensivas para outros de dignidade e esperança ${ }^{8}$. Eis aqui um importante momento para se desvelar esse cenário insuportável pela Sensibilidade Jurídica9 .

Desse modo, percebe-se que, apesar da canção descrever a fruição de uma vida aparentemente de luxo, o que resta no final é um vazio existencial, isto é, nada é capaz de oferecer uma sensação de paz a qualquer pessoa. Aliás, esse comportamento humano de consumismo representado na música é uma das causas da crise ambiental apontado por Saavedra. Logo, a 6 Letra da música Vamos Dançar, de Ed Motta e Rafael Cardoso. Disponível em <www.vagalume.com.br/ed-motta/vamos-dancar. html>. Acesso em 24.07.18.

7 “[...] definitivamente a questão dos direitos humanos é uma questão de alteridade. Não podemos falar de Direitos humanos ignorando o componente da alteridade que o constitui em estrutura. A alteridade é o centro de gravidade dos Direitos humanos, seu equilíbrio vital e existencial". (WARAT, 2010, p. 116)

8 O futuro desejável, sustentável, somente se viabiliza pela persistência das utopias assimétricas, carregadas de esperanças e devires, no momento presente". (AQUINO, 2017, p. 216)

9"Para fins deste artigo, propõe-se o seguinte Conceito Operacional para essa Categoria Sensibilidade Jurídica: ato de sentir algo junto à pluralidade de seres, lugares, momentos e linguagens e que constitui base indispensável para o aperfeiçoamento do sentimento de Justiça, da Consciência Jurídica e convivência global”. (AQUINO, 2018, p. 18) 
música em comento adverte para que o ser humano tenha um olhar diferenciado diante do crescimento econômico e possa refletir de que não basta dinheiro para ser feliz.

No plano musical, a composição "Vamos dançar" apresenta um ritmo que faz um convite à dança, o que pode metaforicamente significar a inspiração para o ser humano levantar da cadeira, mexer-se e tomar uma atitude. Nesse rumo, possui uma métrica bastante simples, em compasso quaternário e com um pulso constante, pouca variação harmônica e de construção fraseológica melódica que se repete quase que sem variantes do início ao fim da obra.

Com relação ao que Saavedra afirma sobre o caráter ecológico e ambiental, a música "Fábrica", da banda Legião Urbana, permite tecer algumas reflexões, já que a letra dessa canção descreve o seguinte:

\begin{abstract}
Nosso dia vai chegar / Teremos nossa vez / Não é pedir demais: / Quero justiça / Quero trabalhar em paz / Não é muito o que lhe peço / Eu quero um trabalho honesto / Em vez de escravidão / Deve haver algum lugar / Onde o mais forte não / Consegue escravizar / Quem não tem chance / De onde vem a indiferença / Temperada a ferro e fogo? Quem guarda os portões da fábrica? / O céu já foi azul, mas agora é cinza / O que era verde aqui já não existe mais / Quem me dera acreditar / Que não acontece nada / De tanto brincar com fogo / Que venha o fogo então / Esse ar deixou minha vista cansada / Nada demais. ${ }^{10}$
\end{abstract}

Segundo relata Severiano (2017, p. 442), "Descendente de um grupo punk, o Aborto Elétrico, a brasiliense Legião Urbana teve como criador e figura principal [...] Renato Russo [...]. Um ícone do rock brasileiro". Essa letra de Renato Russo encontra elos com o princípio da dignidade da pessoa humana ao descrever a angústia dos trabalhadores de uma fábrica por se sentirem escravizados pelo sistema laboral capitalista e degradante. A música transmite uma mensagem de esperança por dias melhores, de um trabalho digno. Em relação à crise ambiental, "Fábrica" fala do passado e do presente.

Nessa lógica, revela-se que a poluição gerada pela indústria está terminando com a visão de um céu límpido e claro, além de denunciar que a paisagem natural do verde já não existe mais naquele cenário. Ademais, o ar poluído da fábrica causa um cansaço visual no trabalhador indicando que a saúde desse empregado está sendo prejudicada. Logo, uma preocupação significativa apontada por Saavedra em relação a esse aspecto da crise ambiental é possível ser identificada nessa letra de Renato Russo.

Deve-se rememorar, nesse caso, que nenhum ser humano pode ser destituído de uma vida bucólica destruída pela crise ambiental, seja no presente, seja no futuro. A fruição daquilo que os ambientes e os seres proporcionam para tornar a existência humana mais sadia e significativa é expressão que se depreende do artigo $3^{0}$ da Declaração Universal dos Direitos Humanos. Essa afirmação vale, ainda, ao próprio cenário de trabalho, o qual não pode insistir em ambientes ${ }^{11}$ periculosos à saúde do trabalhador e sua família. Ter condições sadias para se desenvolver qualquer atividade de trabalho remunerado é o que preconiza o artigo 23 da referida declaração. A conjugação de ambos artigos firma o entendimento da Sustentabilidade como Direito Humano.

Ao se continuar a entender a letra da música "Fábrica", percebe-se, também, que existe uma construção musical de melodia bastante simples. Todavia, em pontos estratégicos faz uso de acordes perfeitos menores que em equilíbrio com a entonação vocal exprime sentimentos de

10 Letra da música Fábrica, de Legião Urbana. Disponível em <www.vagalume.com.br/legiao-urbana/fabrica.html>. Acesso em 24.07.18.

11 "A sadia qualidade de vida, as condições existentes no ambiente laboral e a dignidade humana são pressupostos básicos para alcançar toda a complexidade inerente à ambiência laboral. O meio ambiente do trabalho é um bem de interesse público, coletivo, protegido pelos direitos difusos. Recorrer ao Poder Judiciário pode ser uma das formas de o trabalhador efetivar o direito a um ambiente laboral digno e saudável". (DE FARIA; HUPFFER; TEIXEIRA 2019, p. 16o) 
dor, tristeza e angústia. No final da música a consonância harmônica é quebrada simbolizando um final que não é feliz.

Segundo Dias (2015, p. 16), "O mundo atualmente estä" enfrentando uma crise ambiental de dimensões nunca antes vistas ao longo da história humana. Essa situação foi causada em grande parte pela intervenção do próprio homem”. Em sentido semelhante, Saavedra (2014, p. 28 , grifos do autor) aduz que "[...] embora a crise ambiental, apoiada por estudos e discursos os quais [...] provêm das Ciências Naturais, [...] não se referem a um fenômeno de causas naturais, mas sociais". Nesse caso, um exemplo da influência do Homem como causa da crise ambiental refere-se a música "Passaredo", de Chico Buarque e Francis Hime cuja letra apresenta-se da seguinte maneira:

Ei, pintassilgo / Oi, pintarroxo / Melro, uirapuru / Ai, chega-e-vira / Engole-vento / Saíra, inhambu / Foge, asa-branca / Vai, patativa / Tordo, tuju, tuim / Xô, tié-sangue / Xô, tié-fogo / Xô, rouxinol, sem-fim / Some, coleiro / Anda, trigueiro / Te esconde, colibri / Voa, macuco / Voa, viúva / Utiariti / Bico calado / Toma cuidado / Que o homem vem aí / O homem vem aí / O homem vem aí / Ei, quero-quero / Oi, tico-tico / Anum, pardal, chapim / Xô, cotovia / Xô, ave-fria / Xô pescador-martim / Some, rolinha / Anda, andorinha / Te esconde, bem-te-vi / Voa, bicudo / Voa, sanhaço / Vai, juriti / Bico calado / Muito cuidado / Que o homem vem aí / O homem vem aí / O homem vem aí. ${ }^{12}$

A representação da crise ambiental em "Passaredo" vai ao encontro ao que Saavedra afirma, que se trata de uma causa "antropogênica [...] o que transforma sua discussão em um problema político e ideológico" (2014, p. 29). Isso porque a canção de Chico Buarque e Francis Hime, quando enfatiza que "O homem vem aí" deixa claro que não existe respeito pela Natureza, pois os homens se aproximam das aves para as matar, o que pode provocar o extermínio das mais variadas espécies.

A música revela, ainda, um enorme valor poético e cultural ao inserir na canção diferentes gêneros de aves da fauna brasileira. Por conseguinte, "Passaredo" pode significar uma preocupação dos compositores com a perseguição injustificada a esses animais. Essa vontade de destruição não é nova e reforça a consideração da Sustentabilidade como Direito Humano, pois quando a Natureza - animais e seus ambientes - se tornam objeto de mercancia, ou seja, são explorados de todas as formas apenas para satisfazer as "necessidades" humanas, a $v$ vida $^{13}$, entendida como parceira obrigatória ao nosso desenvolvimento, perde todo o significado - existencial e legal (artigo 3o da Declaração Universal dos Direitos Humanos).

Em realidade, por meio das palavras dirigidas aos pássaros - te esconde, voa, some, entre outros -, que são entoadas na música, pode-se deduzir que o ensinamento que se quer deixar é do cuidado que é necessário ter na preservação das diferentes espécies de aves, mas não somente estas e, sim, de toda a fauna.

Outro ponto que merece menção é de que a letra de "Passaredo", unida às questões de ordem musical, em conjunto formam uma verdadeira obra de arte. Melodicamente, os compositores utilizam um motivo praticamente em ostinato, ou seja, que se repete de maneira constante ao longo de toda a música, mas com alternâncias de altura (notas musicais) que quebram com a sensação de monotonia sonora.

12 Letra da música Passaredo, de Chico Buarque e Francis Hime, 1976. Disponível em <www.vagalume.com.br/chico-buarque/ passaredo.html>. Acesso em 24.07.18.

$13 \mathrm{O}$ pensamento de Hadot (2006, p.306), nesse momento, esclarece: "[...] Com a personificação da natureza, que se operou a partir do século IV antes da nossa era, assumiu-se que era a própria Natureza que se recusava a desvelar seus segredos. Essa representação metafórica podia significar que a natureza encobre em si mesma virtualidades, razões seminais ocultas que podem se manifestar por si mesmas ou trazidas à luz pela constrição da magia e da mecânica. Ela também pode significar que os fenômenos naturais são difíceis de conhecer, notadamente em seus aspectos invisíveis, quer se trate de átomos ou de partes interiores do corpo. Por isso, quando o microscópio abriu para o homem o universo do infinitamente pequeno, os cientistas puderam proclamar que haviam descoberto os segredos da natureza". 
Todos esses fatores são sustentados por uma base harmônica que foge da regra geral, isto é, do padrão tradicional encontrada em várias canções e que buscam de modo massivo incutir no ouvinte impressões de repouso (tônica) e tensão (dominante), que, em tese, são mais atrativas e "agradáveis".

Em sentido oposto, a harmonia utilizada na presente obra musical utiliza-se de dissonâncias constantes e de modulações que contribuem para um pisar mais sólido da melodia e, não obstante também ter um centro tonal pré-definido, a estranheza que os intervalos musicais escolhidos provocam em que escuta essa música em muitos momentos encontra apoio no acorde da tônica.

Acredita-se que a crise ambiental não deve ser uma expressão utilizada somente para dar força a um discurso politicamente correto, sem a profundeza de reflexões e de ações humanas significativas, conforme se depreende de Dias (2015, p. 16):

\section{A crise ambiental não é um termo qualquer. É um conceito amplamente aceito e reflete uma realidade que se caracteriza como um momento crítico, uma encruzilhada em que a humanidade se encontra, cheia de incertezas, mas que exige uma urgente tomada de decisões.}

Uma passagem musical que se relaciona com a citação acima é a seguinte: "Por que esperar se podemos começar tudo de novo / Agora mesmo / A humanidade é desumana / Mas ainda temos chance / O sol nasce pra todos / Só não sabe quem não quer"14.

Nessas palavras, Legião Urbana viabiliza uma reflexão na direção de que adverte as pessoas que não há mais tempo a perder, isto é, o momento para pensar e agir é aqui e agora, não importa o quanto o homem é cruel com o planeta Terra, ainda há esperança, ainda existem caminhos.

Além do mais, essa estrada é para todos os seres vivos e, especialmente em relação aos seres humanos, é presumível que muitos não querem enxergar a verdade, qual seja, de que o mundo vive uma grave crise ambiental. Não é possível adiar providências.

De certo modo, essa letra vai ao encontro sobre o que Saavedra (2014, p 29) disserta sobre a crise ambiental. Ao se parafrasear o autor, compreende-se que a crise ambiental é um fenômeno político, e mais, de um problema político complexo, já que a sociedade humana possui múltiplas diferenças culturais, sociais e geográficas. De fato, essas diferenças culturais apontadas pelo autor ficam mais evidentes quando se observa a produção musical das múltiplas localidades, particularmente em relação à música popular, porque em teoria cada artista reflete o seu contexto pessoal, sua visão de vida e de mundo.

Existem canções com os mais variados temas. Cada qual demonstra um pensamento e um olhar diferenciado em relação seu verdadeiro contexto. Mesmo num único gênero musical, como o pop, evidencia-se essa disparidade, como se pode observar:

Apesar da aparente unidade, o posicionamento pop é bastante diversificado. Há subgrupos que pretendem combinar o pop-rock com ritmos brasileiros mais regionais; outros que se diferenciam por se alinharem a diferentes correntes da música norteamericana (rock progressivo, jazz-rock etc.); outros exploram a música de outras origens como o reggae jamaicano e outros ritmos caribenhos; outros ainda cultivam outros ritmos norte-americanos como o hip-hop, o funk etc. A adesão a uma ou outra proposta vai implicar em investimentos éticos diferenciados. (COSTA, 2011, p. 235, grifos do autor).

14 Trecho da música Quando o Sol Bater na Janela do teu Quarto, de Legião Urbana. Disponível em <www.vagalume.com.br/legiaourbana/quando-o-sol-bater-na-janela-do-teu-quarto.html>. Acesso em 25.07.18. 
A partir desse argumento, no Brasil, o movimento musical conhecido como "Tropicalismo", surgido no final da década de 6o com Caetano Veloso e Gilberto Gil, "[...] misturava influências da música pop internacional, em especial dos Beatles, com a utilização do instrumental eletroeletrônico [e] de várias vertentes de nossa música" (SEVERIANO, 2017, p. 383). Caetano Veloso, na música Terra, de 1978, canta alguns versos que requerem comentários:

Quando eu me encontrava preso, na cela de uma cadeia / Foi que eu vi pela primeira vez, as tais fotografias / Em que apareces inteira, porém lá não estava nua / E sim coberta de nuvens / Terra, terra, / Por mais distante o errante navegante / Quem jamais te esqueceria. ${ }^{15}$

A letra expõe um momento especial de revelação interior no qual o artista, num momento de grande solidão, se dá conta da imensidão do planeta Terra em imagens fotográficas. De forma poética e sentimental a canção denota uma contemplação e veneração pela beleza do mundo ao mesmo tempo em que percebe o quanto a Terra é pequena diante da grandeza do universo.

Esse pequeno trecho musical de Caetano Veloso pode ser relacionado à obra de Saavedra (2014), no momento em que esse explica que no século XX, a percepção de mundo transformou-se, porque o planeta tornou-se pequeno e frágil e o homem pôde enxergar a Terra do espaço sideral e constatar, literalmente, esse diferente ponto de vista.

Depreende-se ainda, dos ensinamentos do supracitado autor, que a ação do ser humano, nesse modelo contemporâneo de civilização industrial, ameaça o equilíbrio do ecossistema global (crise ambiental global), causas antropogênicas. Outrossim se percebe que podem existir fenômenos naturais e asteroides capazes de colocar em risco a vida da espécie humana e dos demais seres vivos. Enfim, há uma nova percepção e pensamento em relação ao planeta nesse novo mundo que agora já se apresenta divido em estados-nações (SAAVEDRA, 2014, p. 25/43).

Fazendo um parêntese, esse cenário lembra a clássica canção "Imagine ${ }^{16 "}$, de John Lennon, na qual exterioriza o desejo de viver num mundo sem guerras e sem fronteiras, ou seja, de habitar num mundo no qual não existam países, politicamente divididos, e que todas as pessoas possam viver em paz. Afinal de contas, do espaço sideral não se enxerga um mapa múndi e as formas mesquinhas de se apropriar da vida se esvaem em nossas mãos como as areias do tempo.

Infelizmente, bem ou mal, em realidade o planeta encontra-se demarcado. Nesse contexto, Saavedra (2014, p. 18/19) esclarece, por exemplo, que os países de primeiro mundo (que são a minoria), evidenciam-se como capitalistas e desenvolvidos; já os de segundo mundo, encontram-se classificados como países europeus de sistema comunista, mas com altos índices de industrialização; e os de terceiro mundo (que são a grande maioria), pertencem ao grupo de países considerados subdesenvolvidos. Além desses fatores, outras expressões de sentido semelhante e que são utilizadas para dividir o mundo, politicamente/economicamente, são Norte e Sul. Esta (Sul) representa o terceiro mundo (países periféricos), e aquela (Norte), o primeiro mundo (países centrais - o centro).

Acredita-se que a música rompe com essas barreiras culturais porque concepções musicais do Norte se fundem com as do Sul e vice-versa. A título de exemplos, o rock (norte) tocado por brasileiros (sul), a bossa-nova (sul), servindo de arranjos às músicas norteamericanas (norte).

15 Trecho da música Terra, de Caetano Veloso. Disponível em <www.vagalume.com.br/caetano-veloso/terra.html>. Acesso em 25.07.18.

16 Letra disponível em <www.letras.mus.br/john-lennon/9o/>. Acesso em 25.07.18. 
No rock gaúcho, essa conjuntura cultural e artística é verificável quando da análise de músicas e letras de certas composições. Nesse rumo, em "Filmes de Guerra, Canções de Amor", da banda Engenheiros do Hawaii, que mescla tais características, um trecho da canção faz uma crítica à imprensa e às Nações Unidas que comportam três observações enfáticas: a) o fragmento aborda um quadro pessimista no qual a mídia está sempre divulgando más notícias, o que em certa medida dá a entender que tal atitude fomenta nas pessoas uma descrença em relação a dias de paz.

Por conta desse cenário, as tragédias humanas normalmente se tornam um prato cheio para a indústria cinematográfica; b) em contraponto a isso, o trecho da música demonstra não haver sentido na política das Nações Unidas, pois conforme sejam os interesses dos diferentes países, a desunião por meio de guerras configura-se inevitável; e, c) por último, o excerto deixa claro que não importa o lado pelo qual se esteja, numa guerra não existem vencedores, somente perdedores. Confira-se:

\footnotetext{
Filmes de guerra, canções de amor / Manchetes de jornal, ou seja lá o que for / Há sempre uma estória infeliz / Esperando uma atriz e um ator / Há vida na terra, há rumores no ar / Dizendo que tudo vai acabar / (Mais uma estória infeliz / Esperando um ator e uma atriz) / Não tenho medo de perder a guerra / Pois no fim da guerra todos perdem / No fim das contas as Nações Unidas / Estão sempre prontas pra desunião / Não tenho medo de perder você / Desde o início eu sabia / Era só questão de dias / Um dia iria acontecer ${ }^{17}$.
}

O arranjo musical dessa canção é coerente com o texto poético. A pegada rock da banda, ao usar a guitarra elétrica, produz sons com acordes fortes se alternando com alguns contornos melódicos em contraponto com a melodia vocal. Nesse aspecto, não se trata de uma "batida" simplória que se repete do início ao fim da música, isto é, a guitarra imprime um forte significado sonoro no conjunto da obra.

Em relação ao baixo elétrico, é possível observar que, por mais que faça às vezes de uma base de acompanhamento, o ouvinte mais atento consegue perceber que há um groove ritmicamente bem construído, que se fosse destacado ou recortado do restante das outras vozes (instrumentos), ainda teria material sonoro importante a ser desfrutado.

No que concerne à bateria, apesar de se inspirar em estilo alienígena, em momentos mais específicos adquire ares de brasilidade ao se misturar aos arranjos de percussão que repercutem notas de um tamborim.

Dando sequência, constata-se que os Engenheiros do Hawaii apresentam predileção sobre o tema "guerra". Numa outra música da referida banda, um pequeno trecho de letra ilustra essa dedução ao exprimir que "Somos um exército, o exército de um homem só / No difícil exercício de viver em paz / Somos um exército, o exército de um homem só"18.

Os arranjos desta música, de forma semelhante a anterior, repetem a congruência instrumental e vocal na execução e interpretação. Todavia, o que importa neste momento é evidenciar que essas poucas palavras podem simbolizar que, no fundo, a paz no mundo depende de cada um dos seres humanos, depende de cada um fazer sua parte. Trata-se de uma tarefa árdua, mas fundamental. Ressalta-se que todas essas reflexões podem ser transpostas para a temática da crise ambiental.

Ter essa consciência é crucial, pois o problema de um é o problema de todos, visto que "a atual crise ambiental é planetária [e] envolve de um modo ou de outro todo o planeta. São exemplos, entre outros, a redução da camada de ozônio e o efeito estufa, que provocam mudanças climáticas" (DIAS, 2015, p. 16).

17 Trecho da música Filmes de Guerra, Canções de Amor, de Engenheiros do Hawaii. Disponível em <www.vagalume.com.br/ engenheiros-do-hawaii/filmes-de-guerra-cancoes-de-amor.html>. Acesso em 26.07.18.

18 Trecho da música O Exército de um homem só, de Engenheiros do Hawaii. Disponível em <https://www.vagalume.com.br/ engenheiros-do-hawaii/o-exercito-de-um-homem-so.html>. Acesso em 26.07.18. 
Nesse cenário, no capítulo 3 da parte I, Saavedra (2014, p. 46/47), ao escrever sobre a crise ambiental, apresenta um imaginário catastrófico ilustrando cinco tópicos relevantes a saber: a) guerra nuclear limitada: que apesar de se concentrar no hemisfério norte, provocaria uma catástrofe planetária, inverno e outono nuclear, nuvens de fumaça encobririam a luz solar alterando a temperatura do planeta e provocando um colapso na agricultura; b) revolução industrial: efeito estufa (gases químicos, etc.), aumento da temperatura do planeta; c) destruição da camada de ozônio (pelos CFCs): radiação ultravioleta capaz de alterar o DNA dos seres visos e provocar vários problemas no ecossistema; d) destruição da cobertura florestal (pulmão do planeta) do planeta: com objetivos de exploração comercial, cultivo agropecuário, expansão do solo urbano; e, e) crescente produção de resíduos industriais e urbanos: poluição, que supera a capacidade de reciclagem natural e envenena o planeta.

Todos esses pontos permitem ao ser humano se preocupar em relação às incertezas quanto ao futuro do planeta Terra. Aliás, segundo Dias "o futuro será o resultado do que faremos hoje em dia" (2015, p. 18). No entanto, segundo Aquino, "[...] percebe-se que há uma falta de Compreensão da Sustentabilidade como Virtude capaz de mitigar a degradação social, ambiental, econômica, cultura e política em que o planeta está imerso" (2014, p. 345). Entretanto, uma das alternativas para se vencer essa incompreensão possa estar relacionada à interdisciplinaridade entre os diferentes campos do saber.

Por esse motivo, ao se analisar a letra da música "Herdeiros do Futuro", de Toquinho, é possível refletir se ainda teremos um modo saudavelmente habitável. Vive-se o hoje sem ter responsabilidade com o amanhã, na contramão da sustentabilidade. Como se pode ler:

A vida é uma grande amiga da gente / Nos dá tudo de graça pra viver / Sol e céu, luz e ar
/ Rios e fontes, terra e mar / Somos os herdeiros do futuro / E pra esse futuro ser feliz /
Vamos ter que cuidar / Bem desse país / Vamos ter que cuidar / Bem desse país / Será
que no futuro haverá flores? / Será que os peixes vão estar no mar? / Será que os arco-íris
terão cores? / E os passarinhos vão poder voar? / Será que a terra vai seguir nos dando /
O fruto, a folha, o caule e a raiz / Será que a vida acaba encontrando / Um jeito bom da
gente ser feliz?

As indagações entoadas na bela melodia da referida canção, deixa claro que "A escolha do desenvolvimento sustentável não é uma simples opção, mas aparentemente é a única solução possível. A capacidade da Terra para atender às necessidades dos seres humanos está no limite" (DIAS, 2015, p. 18).

Dessa forma, urge compreender que o ser humano será o herdeiro de seu do futuro que criar e desejar, seja positivo ou negativo. Nesse contexto, a música acima faz um apelo aos ouvintes no sentido de advertir para a necessidade de se pensar nas responsabilidades que o Homem deve ter para com o planeta Terra. Por esse motivo, a Sustentabilidade, entendida como Direito Humano, não pode ser uma ideologia fraca, mas forte, capaz de incitar a mudança das nossas atitudes no momento presente. Essa é a consciência que previne a destruição de nosso entorno causado pela acentuada crise ambiental mundial e assegura um futuro sadio.

Com essa canção, denota-se que a vida somente faz sentido havendo a própria vida. A poluição turba a visão e encobre as estrelas. Toda a água do mundo, de uma forma ou de outra encontra-se interligada. Os lixos produzidos pela população mundial e que são jogados ao mar viajam muito longe, matam e poluem diversas espécies de animais. Ressalta-se que o problema de um é o problema de todos. De forma simples, a letra instiga que é preciso cuidar da fauna, da flora, da terra e do ar.

19 Letra da música Herdeiros do Futuro, de Toquinho. Disponível em <https://www.vagalume.com.br/toquinho/herdeiros-dofuturo.html>. Acesso em 26.07.18. 
O arranjo musical escolhido na interpretação de "Herdeiros do Futuro", não precisou de batidas fortes de um tambor para se fazer ouvida, nem de um efeito overdrive de uma guitarra elétrica de heavy metal, nem mesmo dos sons pesados de um teclado sintetizador de uma banda de rock. Em questões de timbre, utilizou-se simplesmente a beleza acústica de um violão e a voz humana bem interpretada por Toquinho.

Por derradeiro, é plausível reconhecer que o estudo do tema acerca da crise ambiental não se exaure na investigação de textos científicos. Por meio das artes, especificamente da música popular, existem fontes de pesquisa significativas e que fornecem materiais para os debates nessa seara. Urge aproveitar-se de cada novo soar de uma canção, posto que os músicos continuarão a produzir novas composições ligadas à realidade atual do planeta Terra e, nesse caso, inspirar na humanidade a consciência sobre a necessidade da Sustentabilidade em sua dimensão ambiental.

Por derradeiro, é plausível reconhecer que o estudo do tema acerca da crise ambiental não se exaure na investigação de textos científicos, pois por meio das artes, especificamente da música popular, existe uma fonte de pesquisa significativa para os debates nessa seara e que se renova em cada novo soar de uma canção, posto que os músicos continuarão a produzir novas composições ligadas à realidade atual do planeta Terra.

\section{CONCLUSÃO}

A pesquisa buscou relacionar a crise ambiental e suas representações na música popular brasileira vindo a confirmar de forma positiva a hipótese sustentada, isto é, de que a música popular brasileira, na seara da sustentabilidade, possibilita ampliar e esclarecer a necessidade de maior debate sobre a crise ambiental.

Desse modo, foi possível estabelecer um desenvolvimento com o foco na sustentabilidade em sua dimensão ambiental, não obstante em alguns momentos ter sido necessário adentrar nas dimensões sociais e econômicas a fim de complementar as reflexões críticas sobre o assunto.

Para tanto, abordou-se na primeira parte deste trabalho acerca da importância da música popular na temática da sustentabilidade e, num segundo momento, dissertou-se mais especificamente nas representações da crise ambiental na música popular brasileira.

Desse modo, a investigação apontou que é viável relacionar Direito e Arte e que a música pode favorecer o debate relacionado à crise ambiental, porque por meio da linguagem artística, o compositor consegue perceber o seu próprio contexto e com isso transmitir ideias, sentimentos, pensamentos e mensagens que podem contribuir para elevar a consciência humana sobre esse problema. É a música que aguça nossa sensibilidade, inclusive jurídica, e forma sentimentos capazes de provocar a existência de outros cenários mais sadios, de maior significado ao viver e conviver, e demanda as atitudes necessárias para se trazer esse mundo interior ao exterior.

Nesse sentido, o estudo mostrou que é possível estabelecer relações entre a crise ambiental e a música popular brasileira de modo que a comunidade acadêmica possa buscar subsídios para além dos textos científicos na área e encontrar outras fontes de reflexões e de possíveis soluções a esse problema de âmbito planetário.

Demonstrou-se que por meio da música popular brasileira é possível fomentar o debate sobre a crise ambiental. Todavia, a ferramenta de análise não se restringe somente às letras das canções, isto é, é possível explorar inclusive às intenções do artista no âmbito dos arranjos e da construção musical. 
Do mesmo modo que um trecho de canção aponta para uma situação específica, paralelamente existe um suporte sonoro ligado a questões de melodia, ritmo e harmonia que respaldam aquilo que a composição procura comunicar, expressar ou simbolizar.

Percebeu-se por meio da análise das composições que existe uma gama muita diversificada de expressões musicais a serem exploradas. Por exemplo, muitas canções apresentaram um quadro mais otimista e esperançoso sobre a crise ambiental, enquanto outras se revelaram mais pessimistas.

Todavia, em grade parte, as letras procuraram questionar o problema e advertir sobre as causas e consequências da crise ambiental, não somente em âmbito local como também mundial. Nesse caso, verificou-se que nas músicas, no plano poético, encontram-se uma diversidade de temas ligadas à crise ambiental, tais como o consumismo, vida de luxo, exploração da mão de obra, caça ilegal de animais silvestres, descrença na humanidade, esperança quanto a um futuro melhor, maior consciência quanto à finitude dos recursos naturais e à fragilidade do planeta Terra, poluição de todas as espécies, crítica quanto ao cenário político, guerras, natureza. Esse é o modo que se compreende a Sustentabilidade como Direito Humano.

Conclui-se que existe um amplo material doutrinário, literário e musical que merecem ser explorados, já que se trata de um tema que requer uma preocupação, pesquisa, reflexões e cuidados que acompanharão a humanidade ao longo de todos os tempos. Por fim, as representações da crise ambiental na música popular brasileira permitem a continuidade do assunto em outros artigos, investigações científicas e debates no âmbito das Teorias da Sustentabilidade. Por esse motivo, observou-se que a primeira hipótese descrita na Introdução deste artigo se confirmou, pois, a música popular brasileira, conjugada à matéria da Sustentabilidade como Direito Humano, amplifica, potencializa e elucida a imprescindibilidade de maiores discussões sobre a crise ambiental

\section{REFERÊNCIAS}

AQUINO, Sérgio Ricardo Fernandes de. (Contra o) eclipse da esperança: escritos sobre a(s) assimetria(s) entre direito e sustentabilidade. [recurso eletrônico]. Itajaí, (SC): Editora da UNIVALI, 2017

AQUINO, Sérgio Ricardo Fernandes de. A mediação como experiência moral na pósmodernidade: reflexões ao desenvolvimento de uma política publica. In: FAGÚNDEZ, Paulo Roney Ávila; GOULART, Juliana Ribeiro; GONÇALVES, Jéssica. Mediação como política pública. Florianópolis: EMais, 2018, p. 18.

AQUINO, Sérgio Ricardo Fernandes de. Por uma cidadania sul-americana: fundamentos para a sua viabilidade na UNASUL por meio da Ética, Fraternidade, Sustentabilidade e Política Jurídica. Saarbrücken: Novas Edições Acadêmicas, 2014.

COPLAND, Aaron. Como ouvir e entender música. São Paulo: É Realizações, 2013.

COSTA, Nelson Barros da. Música popular, linguagem e sociedade: analisando o discurso literomusical brasileiro. Curitiba: Appris, 2011. 
DE FARIA, Claudia Maria Petry; HUPFFER, Haide Maria; TEIXEIRA, Paulo José Zimermann. Direito fundamental à qualidade do ambiente laboral e justiça do trabalho: uma abordagem empírica. Novos Estudos Jurídicos, [S.1.], v. 23, n. 1, p. 158-187, abr. 2018. ISSN 2175-0491. Disponível em: <https://siaiap32.univali.br/seer/index.php/nej/article/view/12790/7271>. Acesso em: 14 fev. 2019. doi:http://dx.doi.org/10.14210/nej.v23n1.p158-187.

DIAS, Reinaldo. Sustentabilidade: origem e fundamentos; educação e governança global; modelo de desenvolvimento. São Paulo: Atlas, 2015.

HADOT, Pierre. O véu de Î́sis: ensaio sobre a história da ideia de natureza. Tradução de Mariana Sérvulo. São Paulo: Loyola, 2006

OLIVEIRA, Regis Fernandes de. Direito e arte. São Paulo: Malheiros, 2017.

PASOLD, Cesar Luiz. Metodologia da pesquisa jurídica: teoria e prática. 13. ed. Florianópolis: Conceito Editorial, 2015.

SAAVEDRA, Fernando Estenssoro. História do debate ambiental na política mundial 1945-1992: a perspectiva latino-americana. Ijuí, (RS): Editora UNIJUÍ, 2014.

SEVERIANO, Jairo. Uma história da música popular brasileira: das origens à modernidade. 4. ed. São Paulo: Editora 34, 2017.

TAVARES, Isis Moura; CIT, Simone. Linguagem da música. Curitiba: InterSaberes, 2013.

WARAT, Luís Alberto. A rua grita Dionísio! direitos humanos de alteridade, surrealismo e cartografia. Tradução de Vívian Alves de Assis, Julio Cesar Marcellino Júnior e Alexandre Morais da Rosa. Rio de Janeiro: Lúmen Juris, 2010.

ZAGONEL, Bernadete. Arte na educação escolar. Curitiba: InterSaberes, 2012. 